\title{
KAJIAN MODEL PENGEMBANGAN SDM PARIWISATA DI KAWASAN JATIGEDE KEC. DARMARAJA KAB. SUMEDANG
}

\author{
ISNIAR BUDIARTI $^{1 *}$, MUHAMMAD IFFAN $^{2}$, KANI MAHARDIKA $^{3}$, \\ SELFA SEPTIANI AULIA ${ }^{4}$, LIA WARLINA ${ }^{5}$, SUFA' ATIN $^{6}$ \\ Program Studi Manajemen ${ }^{1,2}$, Program Studi Perencanaan Wilayah dan Kota ${ }^{3,4,5}$, \\ Program Studi Teknik Informatika ${ }^{6}$ \\ Universitas Komputer Indonesia \\ Jl. Dipati Ukur No. 112-116, Bandung 40132 \\ *e-mail: isniar.budiarti@email.unikom.ac.id
}

\begin{abstract}
The emergence of community unrest affected by the construction of the Jatigede Reservoir as one of the priority destinations for national scale development which is directed as a special economic tourism strategic area in Sumedang Regency. This activity was carried out to study the development of a tourism human resource model in Karangpakuan Village and Paku Alam as a village that has the potential to become a Tourism Village. The location of the activity was carried out in these two villages which were the relocation of the Jatigede Reservoir construction. The method used is descriptive qualitative by conducting interviews with Pemdes, Bumdes, local communities, Kompepar, farmer groups and youth organizations; data classification; SWOT analysis. The results of the activity showed that the two villages in the Jatigede area had the strength of cultural tourism, nature tourism and pilgrimage tourism, but the community's readiness was not optimal due to a lack of skills and human resource capabilities. Promotions need to be carried out through invitations to national and international local media, or promotion using digital platforms, this can be used as an opportunity for MSMEs and food craftsmen when holding cultural activities, but the obstacle faced by the two Tourism Villages is the unpreparedness of human resources. The result of this activity is a study of the human resource model for tourism in Karang Pakuan and Pakualam which involves 3 (three) aspects, namely Attitude (Attitude), Skill (Skill); and Knowledge.
\end{abstract}

Key words: Tourism Village, Tourism HR Model

\section{ABSTRAK}

Munculnya keresahan masyarakat yang terkena dampak dari pembangunan Waduk Jatigede sebagai salah satu destinasi yang menjadi prioritas pengembangan skala nasional yang diarahkan sebagai kawasan strategis pariwisata ekonomi khusus di Kabupaten Sumedang. Kegiatan ini dilakukan untuk mengkaji pengembangan model SDM pariwisata yang ada di desa karangpakuan dan paku alam sebagai desa yang memiliki potensi untuk menjadi Desa Wisata. Lokasi kegiatan dilakukan di Dua desa ini yang menjadi relokasi dari adanya pembangunan Waduk Jatigede. Metode yang digunakan Deskriptif kualitatif dengan cara melakukan wawancara Pemdes, Bumdes, Masyarakat sekitar, Kompepar, kelompok tani dan karang taruna; klasifikasi data; analisis SWOT. Hasil kegiatan diperoleh bahwa kedua desa di kawasan jatigede 
ini memiliki kekuatan wisata budaya, wisata Alam dan wisata ziarah, namun kesiapan masyarakat belum optimal karena kekurangan keterampilan dan kemampuan SDM. Perlu dilakukan promosi melalui undangan media lokal nasional dan internasional, ataupun Promosi menggunakan platform digital, hal ini bisa dijadikan sebagai peluang UMKM dan pengrajin makan pada saat mengadakan kegiatan kebudayaan, namun kendala yang dihadapi oleh kedua Desa Wisata ini adalah ketidaksiapan SDM. Hasil kegiatan ini adalah kajian model SDM pariwisata di karang pakuan dan pakualam yang menyangkut 3 (tiga) aspek, yaitu Attitude (Sikap), Skill (Keterampilan); dan Knowledge (Pengetahuan).

Kata kunci: Desa Wisata, Model SDM Pariwisata

\section{PENDAHULUAN}

Salah satu destinasi yang menjadi prioritas pengembangan skala nasional yang juga diarahkan sebagai Kawasan Strategis Pariwisata Daerah maupun akan direncanakan sebagai Kawasan Ekonomi Khusus adalah Kawasan Jatigede. Kawasan Waduk Jatigede yang berlokasi di 5 (lima) kecamatan terdiri dari 28 (dua puluh delapan) desa. Dari 28 (dua puluh delapan) desa di Kawasan Waduk Jatigede, terdapat 2 (dua) desa yang saat ini sudah mulai mengembangkan kegiatan wisata dengan memanfaatkan keberadaan Waduk Jatigede. Desa tersebut yaitu Desa Pakualam dan Desa Karangpakuan, yang juga merupakan desa relokasi dari adanya pembangunan Waduk Jatigede.

Pengembangan wisata yang ada di kedua desa tersebut saat ini belum diikuti dengan pengembangan Sumber Daya Manusia (SDM) pariwisata yang maju dan berdaya. Walaupun pada saat ini sudah terdapat berbagai komunitas atau kelompok yang mengembangkan kegiatan pariwisata, seperti Komunitas Penggerak Pariwisata (Kompepar), akan tetapi peran Kompepar yang ada di 2 (dua) desa belum maksimal untuk mengembangkan kegiatan pariwisata. Selain itu, Kompepar yang ada masih bersifat swadaya kelompok masyarakat yang secara mental sudah sadar dan siap menjadi pelaku usaha wisata. Sehingga saat ini belum semua masyarakat Desa Pakualam dan Desa Karangpakuan ikut terlibat secara aktif dalam pengembangan pariwisata.

Oleh karena itu, penyiapan dan pengembangan SDM pelaku usaha wisata perlu dilakukan, agar masyarakat tidak hanya menjadi penonton wisata saja, tetapi juga menjadi pelaku yang memanfaatkan keberadaan potensi tersebut. Dengan kondisi SDM yang ada di 2 (dua) desa saat ini, maka perlu dilakukan penyusunan sebuah kajian, yaitu "Pengembangan SDM Pariwisata di Kawasan Waduk Jatigede".

dengan ruang lingkup wilayah kajian terdiri dari 2 (dua) desa, yaitu Desa Pakualam dan Desa Karangpakuan, karena merupakan desa yang sudah ditetapkan sebagai desa wisata.

\section{METODE PELAKSANAN}

Lingkup wilayah lokasi kegiatan kajian pengembangan SDM ini, berada pada 2 (dua) desa yaitu Pakualam dan Karangpakuan yang pada saat ini sudah mengembangkan kegiatan pariwisata dengan memanfaatkan Waduk Jatigede. (Gambar.1) 


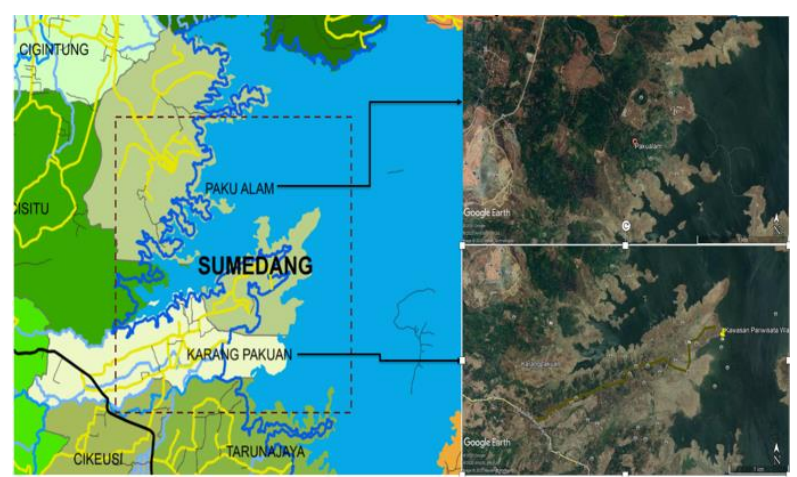

Gambar 1. Peta Lokasi Desa Pakualam dan Karangpakuan

Tim pelaksana adalah dosen di program studi Manajemen, Perencanaan Wilayah Kota (PWK), dan Teknik Informatika. Pelaksanaan kegiatan dimulai dari bulan September 2018 sampai 30 November 2020.

Lingkup substansi pada kegiatan ini dibatasi atas potensi dan permasalahan serta bentuk model rencana pengembangan SDM pariwisata di desa wisata berdasarkan pada 3 (tiga) kegiatan teknis. Kegiatan teknis tersebut tersusun dalam rangkaian kegiatan yang akan dilaksanakan untuk membuat rekomendasi pengembangan SDM dan kelembagaan pariwisata di Kawasan Waduk Jatigede. Adapun tahapannya dimulai dari tahap persiapan, pengumpulan data primer dan sekunder hasil survey lapangan (Gambar 2 dan 3) pengolahan dan analisis data mencakup jenis yang sudah dilakukan, analisis aktor dan peran stakeholder lokal dalam kegiatan pariwisata, analisis pengetahuan dan kemampuan SDM dalam pengembangan kegiatan pariwisata, analisis potensi pengembangan kegiatan pariwisata yang dapat didukung oleh stakeholder lokal sebagai bentuk pengembangan SDM, serta analisis model pengembangan SDM, dan pembuatan rekomendasi dan arahan kebijakan dalam mengembangkan kegiatan pariwisata di Desa Wisata Paku Alam dan Karangpakuan.

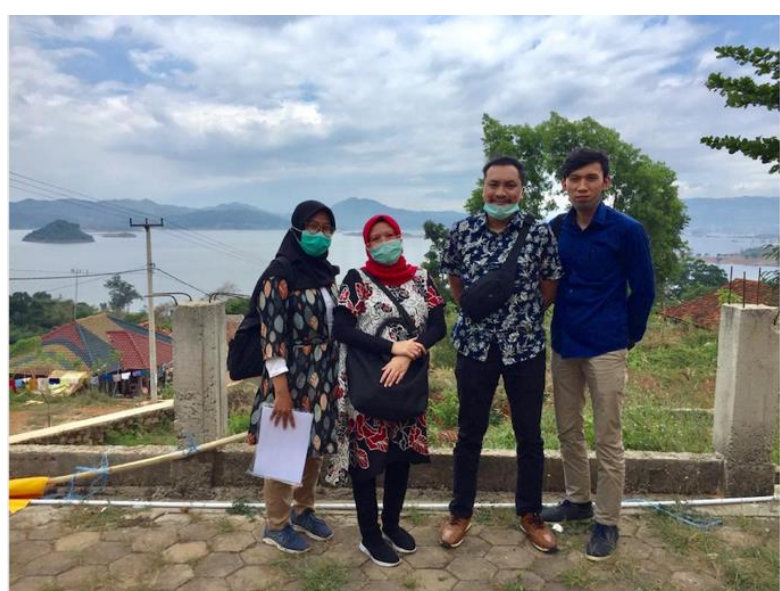

Gambar 2. Kunjungan ke lokasi pengabdian (Desa-desa di Kawasan Waduk Jatigede)

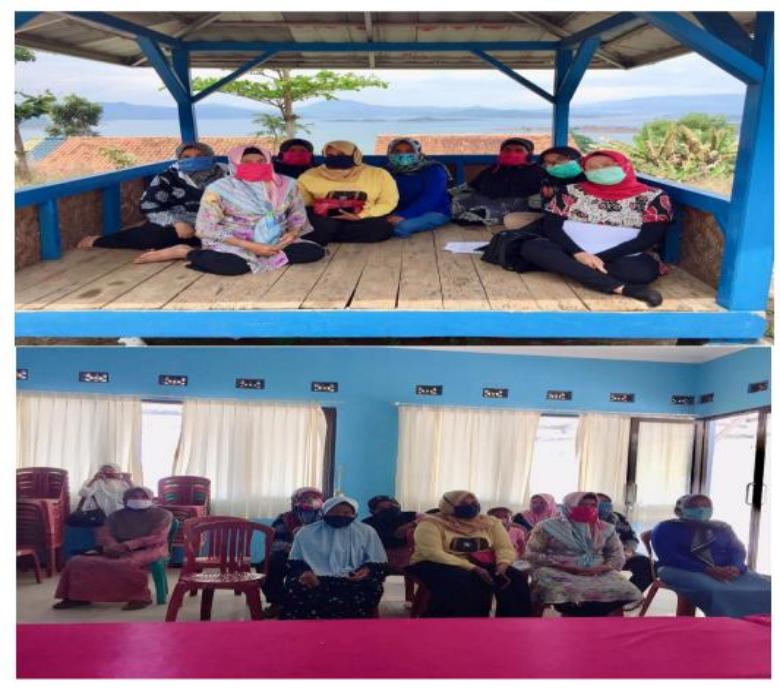

Gambar 3. Diskusi dengan Masyarakat di (Desa-desa di Kawasan Waduk Jatigede)

\section{HASIL DAN PEMBAHASAN}

\section{Inisiasi/ Penjajagan}

Pada tahap inisiasi Tim Pelaksana mengunjungi Desa Paku Alam dan Karangpakuan bertemu dengan Bapak Drs. H. Herman Suryatman, MSi yang merupakan Sekretaris Daerah Kabupaten Sumedang, yang sangat peduli dalam pengembangan SDM pariwisata di desa Karangpakuan dan Pakualam. Pada tahap ini, pelaksana kegiatan 
diberikan arahan kebutuhan akan pengembangan masyarakat di dua desa wisata.

\section{Pengolahan Data dan Analisis}

Hasil dari Kajian model pengembangan SDM pariwisata Di kawasan Jatigede Kec. Darmaraja Kabupaten Sumedang dapat disajikan pada Tabel 1. Informasi ini diperoleh dari wawancara dan observasi langsung.

Tabel 1. Peran dan Permasalahan SDM di Desa Wisata

\begin{tabular}{|c|c|c|}
\hline Kom & Peran SDM & Permasalahan \\
\hline $\begin{array}{l}\text { - } \text { PEMDES, } \\
\text { - } \text { BUMDES } \\
\text { - Masy. } \\
\text { sekitar } \\
\text { - KOMPEP } \\
\text { AR } \\
\text { - Klp. } \\
\text { WANITA } \\
\text { TANI/ } \\
\text { KWT }\end{array}$ & $\begin{array}{l}\text { Menginventarisasi } \\
\text { dan pengelola } \\
\text { potensi wisata, } \\
\text { seperti: } \\
\text { Wisata budaya Di } \\
\text { desa Pakualam } \\
\text { adalah pelatihan } \\
\text { tari, upacara adat, } \\
\text { dan jaipongan. } \\
\text { Wisata alamnya } \\
\text { puncak damar yang } \\
\text { memiliki tempat } \\
\text { pemancingan, } \\
\text { Kampung Buricak } \\
\text { Burinong } \\
\text { wisatawan berfoto, } \\
\text { wisata perahu } \\
\text { mengitari gunung } \\
\text { surian, berenang di } \\
\text { waterboom yang } \\
\text { berada di Dusun } \\
\text { Cilembu, kuliner } \\
\text { nasi liwet dan ikan } \\
\text { bakar. } \\
\text { Wisata ziarah Situs } \\
\text { Cipeuet I-III } \\
\text { Makam Keramat } \\
\text { Deungdeum } \\
\text { Makam Keramat } \\
\text { Puncak Damar } \\
\text { Cisema Keramat } \\
\text { Makama } \\
\text { Astana Leutik } \\
\text { Mangkunagara. }\end{array}$ & $\begin{array}{l}\text { Masih mengandalkan } \\
\text { bantuan-bantuan dari } \\
\text { pihak pemerintah } \\
\text { untuk pengelolaan } \\
\text { kedua desa wisata } \\
\text { tersebut. } \\
\text { Kegiatan di kedua desa } \\
\text { wisata tersebut belum } \\
\text { berkembang dan } \\
\text { wisata budaya, wisata } \\
\text { alam dan ziarah/religi } \\
\text { belum dimaksimalkan } \\
\text { potensinya. } \\
\text { Kesiapan masyarakat } \\
\text { di sekitar destinasi } \\
\text { pariwisata yang masih } \\
\text { belum optimal } \\
\text { Keterbatasan SDM/ } \\
\text { kekurangan SDM di } \\
\text { kedua desa ini. } \\
\text { Kekurangan } \\
\text { Keterampilan dan } \\
\text { kemampuan SDM } \\
\text { dalam pengelolaan } \\
\text { industri pariwisata di } \\
\text { dua desa ini. } \\
\text { Kurangnya promosi di } \\
\text { kedua desa wisata ini } \\
\text { dan informasi hanya } \\
\text { dari mulut ke mulut } \\
\text { Belum efektifnya } \\
\text { wadah digital (website, } \\
\text { social media) untuk } \\
\text { mengarahkan sebagai } \\
\text { panduan/informasi } \\
\text { kepada wisatawan } \\
\text { yang ingin mengetahui } \\
\text { potensi wisata di kedua } \\
\text { desa yang dikelola oleh } \\
\text { masyarakat lokal. }\end{array}$ \\
\hline $\begin{array}{ll}2 . & \text { KARANG } \\
& \text { TARUNA }\end{array}$ & $\begin{array}{l}\text { Pengembangan } \\
\text { usaha Wifi }\end{array}$ & $\begin{array}{l}\text { - Sudah berjalan dengan } \\
\text { baik dan dilakukan } \\
\text { kerjasama dengan PT. } \\
\text { Telkom. Namun, } \\
\text { belum seluruh } \\
\text { masyarakat terpenuhi }\end{array}$ \\
\hline
\end{tabular}

\begin{tabular}{|c|c|c|}
\hline & - $\begin{array}{l}\text { Budidaya Ikan } \\
\text { Lele }\end{array}$ & $\begin{array}{l}\text { Butuh modal untuk } \\
\text { pengembangannya }\end{array}$ \\
\hline \multirow[t]{2}{*}{$\begin{array}{l}\text { 3. Masyarakat } \\
\text { Pelaku } \\
\text { Usaha } \\
\text { UMKM } \\
\text { bekerjasama } \\
\text { dengan } \\
\text { KWT } \\
\text { sebagai } \\
\text { Wadah } \\
\text { Kelompok } \\
\text { Pengrajin } \\
\text { makanan } \\
\text { dan } \\
\text { Kegiatan } \\
\text { Festival } \\
\text { Olahan } \\
\text { Makanan } \\
\text { serta } \\
\text { Souvenir }\end{array}$} & $\begin{array}{l}\text { Potensi unggulan } \\
\text { lainnya di sekitar } \\
\text { pariwisata adalah } \\
\text { sebagai penyedia } \\
\text { kuliner lokal khas } \\
\text { produk lokal Desa } \\
\text { Pakualam dan } \\
\text { Karangpakuan } \\
\text { untuk disuguhkan } \\
\text { kepada } \\
\text { pengunjung/wisataw } \\
\text { an serta berpotensi } \\
\text { untuk menawarkan } \\
\text { Paket Cooking } \\
\text { Class (masakan } \\
\text { khas nasi liwet) } \\
\text { kepada wisatawan } \\
\text { sejak 2017 dan } \\
\text { dapat } \\
\text { dikembangkan } \\
\text { kegiatan festival } \\
\text { tersebut setiap } \\
\text { tahunnya. }\end{array}$ & 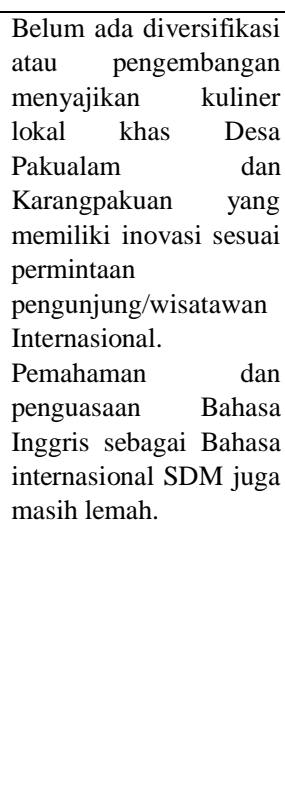 \\
\hline & $\begin{array}{l}\text { - Perahu wisata } \\
\text { - Wisata } \\
\text { Pemancingan }\end{array}$ & $\begin{array}{l}\text { Hambatan penataan } \\
\text { dan pengelolaannya }\end{array}$ \\
\hline $\begin{array}{l}\text { Masyarakat } \\
\text { Sekitar/Ke } \\
\text { pala } \\
\text { Keluarga } \\
\text { pemilik } \\
\text { rumah } \\
\text { dijadikan } \\
\text { homestay }\end{array}$ & 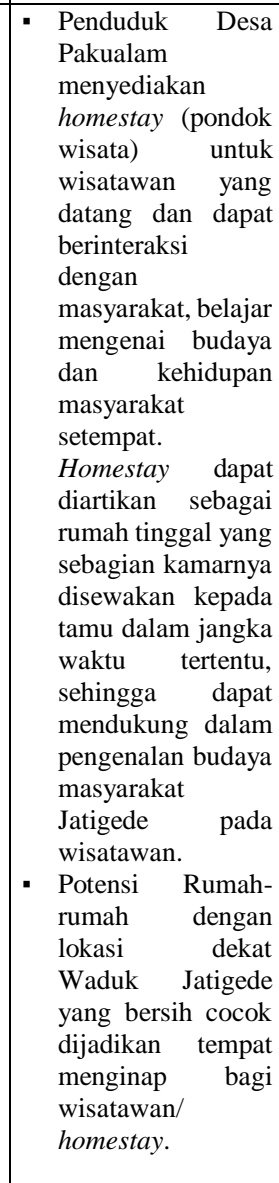 & 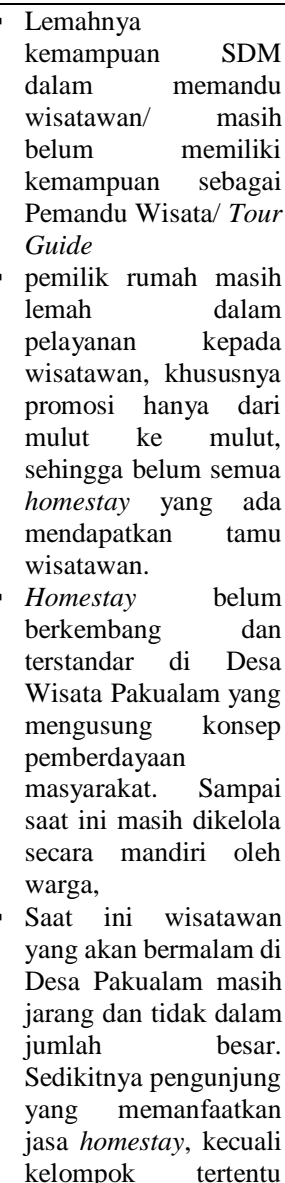 \\
\hline
\end{tabular}




\begin{tabular}{|c|c|c|}
\hline & & $\begin{array}{lr}\text { yang } & \text { sedang } \\
\text { menggunakan Desa } \\
\text { Wisata Pakualam } \\
\text { untuk acara tertentu } \\
\text { seperti penelitian, } \\
\text { kunjungan kerja atau } \\
\text { kegiatan off road. }\end{array}$ \\
\hline $\begin{array}{l}\text { Stakeholder } \\
\text { Pariwisata, } \\
\text { seperti: } \\
\text { Agen } \\
\text { Perjalanan } \\
\text { (Travel } \\
\text { Agent), } \\
\text { Pemandu } \\
\text { Wisata, } \\
\text { serta } \\
\text { pemilik } \\
\text { homestay }\end{array}$ & $\begin{array}{l}\text { Memasarkan } \\
\text { Paket Wisata } \\
\text { Waduk Jatigede } \\
\text { kepada } \\
\text { Wisatawan }\end{array}$ & $\begin{array}{l}\text { Belum ada: } \\
\text { - Agen perjalanan } \\
\text { - Pemandu wisata } \\
\text { (pernah ada namun } \\
\text { beralih ke } \\
\text { kompepar) } \\
\text { - Kurangnya SDM } \\
\text { yang memahami } \\
\text { bidang } \\
\text { kepariwisataan } \\
\text { - Para Stakeholder } \\
\text { Pariwisata kurang } \\
\text { mengenal secara } \\
\text { mendalam potensi } \\
\text { yang ada di Desa } \\
\text { Wisata dan masih } \\
\text { lemahnya } \\
\text { pemahaman } \\
\text { kerjasama } \\
\text { pariwisata diantara } \\
\text { masyarakat. }\end{array}$ \\
\hline
\end{tabular}

Sumber: Hasil Analisis, 2020

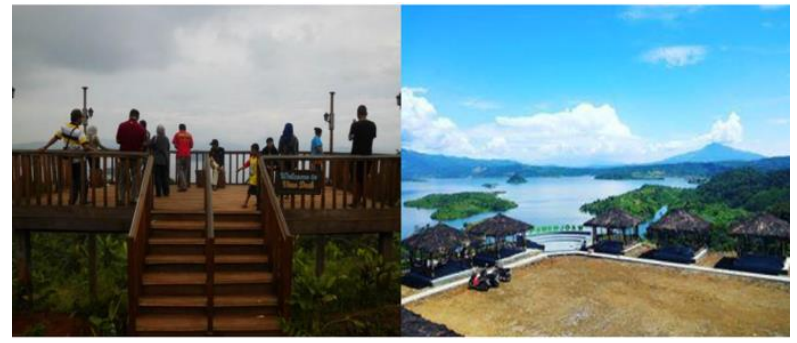

Gambar 4. Pemandangan Alam di Sekitar Waduk Jatigede [1]

\section{Analisis Model SDM Pariwisata Desa Wisata}

Berdasarkan hasil analisis pengolahan dan analisis data, maka Model pengembangan SDM yang direkomendasikan untuk Desa Wisata Paku Alam dan Karangpakuan adalah model SDM Pariwisata berkompetensi yang menyangkut 3 (tiga) aspek utama, yaitu Attitude (Sikap), Skill (Keterampilan); dan Knowledge (Pengetahuan), seperti terlihat pada gambar berikut ini.

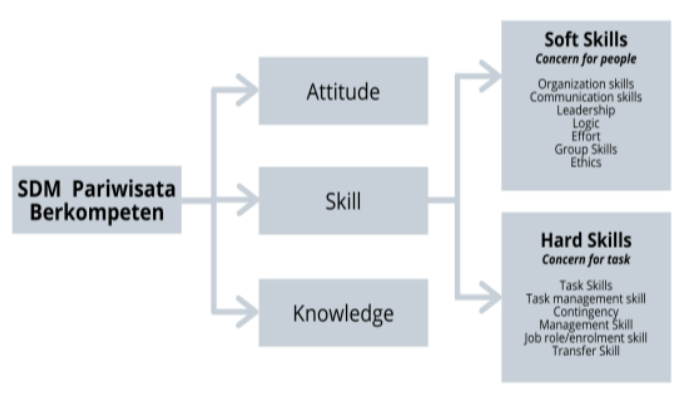

Gambar 5. Model Pengembangan Kompetensi SDM sektor pariwisata

Attitude, Skill dan Knowledge, ketiga hal ini mungkin sudah tidak asing lagi sering kita dengar, dimana Attitude berarti sikap, skill artinya keterampilan dan knowledge berarti pengetahuan. Attitude, Skill dan Knowledge adalah tiga kompetensi yang sudah seharusnya dimiliki oleh setiap orang. Namun apa yang terjadi jika ketiga hal tersebut tidak semuanya dimiliki oleh setiap individu. Bagaimana pentingnya kombinasi ketiga hal ini terutama dalam usaha wisata.

Sebelumnya, kita ulas mengenai pendapat para ahli terkait Attitude, Skill dan dua tipe skill yaitu Hard skill dan soft skill, dan Knowledge. [2] Mengemukakan bahwa Attitude/sikap adalah suatu pola atau perilaku tendensi ataupun kesiapan untuk seseorang agar bisa menyesuaikan diri atau mungkin disebut sebagai adaptasi. Sedangkan Skill /keterampilan berarti mengembangkan pengetahuan yang didapatkan melalui training dan pengalaman dengan melaksanakan beberapa tugas, [3] (Dunette, 1976). Dua tipe skill yang sama pentingnya yaitu Hard skill dan Soft skill.

Hard skill biasanya mengacu pada skill sebagaimana yang didefinisikan oleh Random House Dictionary [4] (dalam Robles, 2012), yaitu kemampuan yang berasal dari pengetahuan, kemampuan praktis, atau kecerdasan untuk melakukan sesuatu dengan baik; kompetensi dalam melakukan sesuatu; 
keahlian atau keterampilan yang membutuhkan latihan tertentu. Hard skill mencakup kompetensi yang terdiri dari spesifikasi pengetahuan, keterampilan dan sikap serta penerapannya dalam suatu pekerjaan berdasarkan pada kriteria unjuk kerja yang dibutuhkan dalam pekerjaan yang meliputi:

1) Keterampilan melaksanakan pekerjaan (Task Skill).

Kompetensi Task Skill yaitu keterampilan untuk mampu melaksanakan tugas pekerjaannya sesuai dengan standar yang disyaratkan oleh tempat kerja [5] (Pusdiknakes, 2004: 2). Kompetensi Task Skill meliputi:

- standard professional practice

Menurut [6] (IBI, 2007: 126) standar professional practice asuhan yang diberikan harus sesuai dengan prosedur/standar yang telah ditetapkan.

- Standar professional ethic

Berdasarkan standar professional ethic harus sesuai dengan etika profesi dengan memperhatikan sikap dan perilaku serta memperhatikan kondisi.

2) Keterampilan mengelola pekerjaan Manajemen (Task Management Skill) Kompetensi Task Skill yaitu kemampuan manajerial mulai dari membuat perencanaan dan mengorganisir tugas-tugas pekerjaannya sampai pada evaluasi dengan efektif dan efisien. Kompetensi Task Skill meliputi kemampuan dalam mengelola beberapa tugas yang berbeda dalam pekerjaan

3) Keterampilan menguasai kemungkinan (Contingency Management Skill) Kompetensi Contingency Management Skill yaitu kemampuan melakukan tindakan dan pengambilan keputusan yang tepat atas suatu masalah dilandasi dengan kemampuan berpikir kritis (Critical Thinking). Kompetensi Contingency Management Skill meliputi tanggap terhadap adanya kelainan dan kerusakan pada rutinitas kerja.

4) Keterampilan mengelola lingkungan kerja (Job/Role skill)

Kompetensi Job/Role Skill yaitu keterampilan untuk berperan serta dan memberikan kontribusi terhadap peran dari pekerjaan yang dijalani. Kompetensi Job/Role harus mampu menghadapi tanggung jawab dan harapan dari lingkungan kerja.

5) Keterampilan beradaptasi (Adaptation Skill) Keterampilan beradaptasi Adaptation Skill yaitu kemampuan untuk beradaptasi/menerapkan keterampilan dan pengetahuannya pada situasi yang baru. Kompetensi Adaptation Skill meliputi:

a) Kemampuan menerapkan keterampilan pada situasi baru

b) Kemampuan berkomunikasi

c) Kemampuan bekerja sama kompetensi

Adaptation Skill meliputi: kemampuan menerapkan keterampilan pada situasi baru (bekerja secara sistematis, bekerja dengan hatihati dan cermat), kesadaran untuk bekerja satu tim (mampu bekerja sama dengan orang lain/klien dalam melakukan tindakan), sikap melayani yang tulus/tanpa unsur paksaan dan membangun komunikasi yang santun (komunikasi efektif) dengan memperhatikan kondisi klien [6] (IBI, 2007: 130).

Soft skills merupakan keterampilan dan kecakapan hidup, baik untuk sendiri, berkelompok, atau bermasyarakat, serta dengan Sang Pencipta. Dengan mempunyai soft skills membuat keberadaan seseorang akan semakin terasa di tengah masyarakat. Keterampilan akan berkomunikasi, keterampilan emosional, keterampilan berbahasa, keterampilan berkelompok, memiliki etika dan moral, santun dan keterampilan spiritual.

Knowledge/Pengetahuan di dalam organisasi hanya bisa melekat di dalam rutinitas, proses, 
praktik, dan norma organisasi. Secara aktif pengetahuan memungkinkan kinerja, problemsolving, pengambilan keputusan, belajar untuk menciptakan value bagi karyawan, organisasi, dan para pemegang sahamnya. [7] James (2004), dalam Kusumadmo (2013). Soft skill memiliki sub elemen yang harus dimiliki dan elemen yang baik untuk dimiliki seperti Tabel 2. berikut.

Tabel 2. Sub skill elemen yang harus dimiliki (must have elements) dan Sub skill elemen yang baik untuk dimiliki (go to

\begin{tabular}{|c|c|c|}
\hline \multicolumn{3}{|c|}{ have elements) } \\
\hline Soft skill & $\begin{array}{c}\text { Sub skill } \\
\text { elemen yang harus } \\
\text { dimiliki } \\
\text { (Must Have } \\
\text { Elements) }\end{array}$ & $\begin{array}{c}\text { Sub skil } \\
\text { elemen yang baik } \\
\text { untuk dimiliki } \\
\text { (Good to have } \\
\text { Elements) }\end{array}$ \\
\hline $\begin{array}{l}\text { Kemampuan } \\
\text { berkomunikasi }\end{array}$ & $\begin{array}{l}\text { - Kemampuan } \\
\text { menyampaikan ide } \\
\text { secara jelas, efektif } \\
\text { dan meyakinkan } \\
\text { baik lisan maupun } \\
\text { tertulis. } \\
\text { - Kemampuan untuk } \\
\text { mempraktikkan } \\
\text { keterampilan } \\
\text { mendengar dengan } \\
\text { baik dan memberi } \\
\text { tanggapan } \\
\text { - Kemampuan } \\
\text { berpresentasi } \\
\text { secara jelas dan } \\
\text { meyakinkan } \\
\text { audience }\end{array}$ & $\begin{array}{l}\text { Kemampuan } \\
\text { menggunakan } \\
\text { teknologi } \\
\text { Kemampuan untuk } \\
\text { berkomunikasi } \\
\text { dengan individu } \\
\text { yang mempunyai } \\
\text { latar belakang } \\
\text { berbeda } \\
\text { Kemampuan untuk } \\
\text { menularkan } \\
\text { kemampuan } \\
\text { komunikasi orang } \\
\text { lain }\end{array}$ \\
\hline $\begin{array}{l}\text { Kemampuan } \\
\text { kepemimpinan }\end{array}$ & $\begin{array}{l}\text { - Mempunyai } \\
\text { pengetahuan teori } \\
\text { dasar } \\
\text { kepemimpinan } \\
\text { - Kemampuan untuk } \\
\text { memimpin suatu } \\
\text { proyek }\end{array}$ & $\begin{array}{lr}\text { Kemampuan } & \text { untuk } \\
\text { memahami } & \text { dan } \\
\text { menjadi } & \text { alternatif } \\
\text { pemimpin } & \text { dan } \\
\text { pengikut. } & \end{array}$ \\
\hline $\begin{array}{l}\text { Kemampuan } \\
\text { berpikir kritis } \\
\text { dan mampu } \\
\text { memecahkan } \\
\text { masalah }\end{array}$ & $\begin{array}{l}\text { - Kemampuan untuk } \\
\text { mengidentifikasi } \\
\text { dan menganalisa } \\
\text { masalah dalam } \\
\text { situasi sulit dan } \\
\text { melakukan } \\
\text { justifikasi } \\
\text { - Kemampuan } \\
\text { memperluas dan } \\
\text { memperbaiki } \\
\text { keterampilan } \\
\text { berpikir, seperti: }\end{array}$ & $\begin{array}{l}\text { - Kemampuan } \\
\text { berpikir lebih luas } \\
\text { - Kemampuan untuk } \\
\text { membuat } \\
\text { kesimpulan } \\
\text { berdasarkan bukti } \\
\text { yang valid } \\
\text { - Kemampuan untuk } \\
\text { menerima dan } \\
\text { memberikan } \\
\text { tanggung jawab } \\
\text { sepenuhnya. }\end{array}$ \\
\hline
\end{tabular}

\begin{tabular}{|c|c|c|}
\hline & $\begin{array}{l}\text { menjelaskan, } \\
\text { menganalisis, dan } \\
\text { mengevaluasi } \\
\text { diskusi } \\
\text { Kemampuan } \\
\text { mendapatkan ide } \\
\text { dan mencari solusi } \\
\text { alternatif }\end{array}$ & $\begin{array}{l}\text { Kemampuan untuk } \\
\text { memahami seseorang } \\
\text { dan mengakomodasi } \\
\text { kedalam suasana } \\
\text { kerja yang beragam }\end{array}$ \\
\hline $\begin{array}{l}\text { Effort atau } \\
\text { upaya }\end{array}$ & $\begin{array}{l}\text { - Kemampuan untuk } \\
\text { mengelola } \\
\text { informasi yang } \\
\text { relevan dari } \\
\text { berbagai sumber } \\
\text { - Kemampuan untuk } \\
\text { menerima ide-ide } \\
\text { baru }\end{array}$ & $\begin{array}{l}\text { Kemampuan } \\
\text { untuk } \\
\text { mengembangkan } \\
\text { keinginan untuk } \\
\text { menginvestigasi } \\
\text { dan mencari } \\
\text { pengetahuan }\end{array}$ \\
\hline $\begin{array}{l}\text { Grup skilll } \\
\text { Kerjasama } \\
\text { tim }\end{array}$ & $\begin{array}{lr}\text { Kemampuan } & \text { untuk } \\
\text { membangun } & \\
\text { hubungan, } & \\
\text { berinteraksi } & \text { dan } \\
\text { bekerja } & \text { secara } \\
\text { efektif } & \text { dengan } \\
\text { lainnya } & \\
\text { Kemampuan } & \text { untuk } \\
\text { memahami } & \text { dan } \\
\text { berperan } & \text { sebagai } \\
\text { anggota. } & \end{array}$ & $\begin{array}{l}\text { Kemampuan untuk } \\
\text { memberikan } \\
\text { kontribusi terhadap } \\
\text { perencanaan dan } \\
\text { mengkoordinasi } \\
\text { kerja grup dan } \\
\text { bertanggung jawab } \\
\text { terhadap keputusan } \\
\text { grup }\end{array}$ \\
\hline $\begin{array}{l}\text { Ethics/ etika, } \\
\text { moral dan } \\
\text { profesional }\end{array}$ & $\begin{array}{l}\text { Kemampuan untuk } \\
\text { memahami krisis } \\
\text { ekonomi, } \\
\text { lingkungan dan } \\
\text { aspek sosial budaya } \\
\text { professional, } \\
\text { Kemampuan untuk } \\
\text { menganalisis } \\
\text { membuat keputusan } \\
\text { pemecahan masalah } \\
\text { yang berkaitan } \\
\text { dengan etika }\end{array}$ & $\begin{array}{l}\text { Kemampuan untuk } \\
\text { mempraktikkan } \\
\text { etika perilaku }\end{array}$ \\
\hline
\end{tabular}

Sumber: Hasil Analisis, 2020

\section{Model Pengembangan Kompetensi SDM} sektor pariwisata Desa Pakualam dan Karangpakuan seperti digambarkan pada gambar 5. di atas, perlu diimplementasikan dengan memperhatikan [8] Peraturan Pemerintah Republik Indonesia Nomor 52 Tahun 2012, Bab I pasal 1 Tentang Kompetensi. Kompetensi adalah seperangkat pengetahuan, keterampilan, dan perilaku yang harus dimiliki, dihayati, dan dikuasai oleh pekerja pariwisata untuk mengembangkan profesionalitas kerja. Sehubungan dengan hal tersebut, maka SDM sektor pariwisata perlu mengikuti pengembangan kompetensi meliputi: 
kompetensi manajerial adalah pengetahuan, keterampilan dan sikap/perilaku yang dapat diamati, diukur, dikembangkan untuk memimpin dan/atau mengelola unit organisasi; kompetensi teknis adalah pengetahuan, keterampilan, dan sikap/perilaku yang dapat diamati, diukur, dan dikembangkan yang spesifik berkaitan dengan bidang jabatan dalam organisasi; kompetensi sosial kultural adalah pengetahuan, keterampilan, dan sikap/perilaku yang dapat diamati, diukur, dan dikembangkan terkait dengan pengalaman berinteraksi dengan masyarakat majemuk dalam hal agama, suku dan budaya, perilaku, wawasan kebangsaan, etika, nilai-nilai moral, emosi dan prinsip, yang harus dipenuhi oleh setiap pemegang jabatan untuk memperoleh hasil kerja sesuai dengan peran, fungsi dan jabatan. Pengembangan kompetensi tersebut dilakukan melalui pendidikan dan pelatihan, seperti seminar, kursus dan pelatihan.

Berdasarkan analisa SWOT untuk pengembangan SDM dengan model kompetensi di Desa Wisata Paku Alam dan Karangpakuan dapat dilihat seperti pada pada tabel 3. berikut.

Tabel 3. Model Kompetensi SDM

\begin{tabular}{|c|c|c|}
\hline $\begin{array}{c}\text { Aspek } \\
\text { Kelemahan }\end{array}$ & $\begin{array}{l}\text { Rekomendasi } \\
\text { dan } \\
\text { Improvement }\end{array}$ & Penjelasan \\
\hline $\begin{array}{l}\text { Kesiapan } \\
\text { masyarakat } \\
\text { pengelola } \\
\text { pariwisata di } \\
\text { kedua desa wisata } \\
\text { masih belum } \\
\text { optimal serta } \\
\text { adanya } \\
\text { Kekurangan } \\
\text { keterampilan dan } \\
\text { kemampuan SDM } \\
\text { dalam pengelolaan } \\
\text { industri pariwisata } \\
\text { di dua desa. }\end{array}$ & $\begin{array}{l}\text { Peningkatan } \\
\text { Hard skill \& Soft } \\
\text { Skill }\end{array}$ & $\begin{array}{l}\text { 1) Peningkatan SDM } \\
\text { yang dibutuhkan dua } \\
\text { desa wisata tersebut } \\
\text { adalah: } \\
\text { 2) Peningkatan Standar } \\
\text { operasional prosedur } \\
\text { yang ditetapkan (SOP) } \\
\text { melalui pelatihan ISO } \\
9001 \text { : 2015 untuk } \\
\text { sistem manajemen } \\
\text { mutu (SMM) } \\
\text { pariwisata. } \\
\text { 3) Peningkatan } \\
\text { kemampuan pimpinan } \\
\text { dalam mengelola } \\
\text { beberapa tugas yang } \\
\text { berbeda dalam } \\
\text { pekerjaan dengan cara } \\
\text { pelatihan leadership }\end{array}$ \\
\hline
\end{tabular}

\begin{tabular}{|c|c|c|}
\hline & & $\begin{array}{l}\text { kolaboratif dalam } \\
\text { mengelola wisata. } \\
\text { 4) Kemampuan } \\
\text { melakukan tindakan } \\
\text { dan pengambilan } \\
\text { keputusan yang tepat, } \\
\text { misalnya dengan cara } \\
\text { diadakan outbound. } \\
\text { 5) Keterampilan } \\
\text { pimpinan dalam } \\
\text { menentukan job role } \\
\text { agar tidak terjadi } \\
\text { tumpang tindih } \\
\text { misalnya: aktivitas } \\
\text { pariwisata paralayang, } \\
\text { dimana tour guide } \\
\text { merangkap menjadi } \\
\text { teknisi paralayang } \\
\text { 6) kemampuan aktor- } \\
\text { aktor pariwisata dalam } \\
\text { beradaptasi dengan } \\
\text { lingkungan baru } \\
\text { keterampilan- } \\
\text { keterampilan teknis di } \\
\text { bidang pariwisata dan } \\
\text { hospitality (untuk } \\
\text { homestay). }\end{array}$ \\
\hline $\begin{array}{l}\text { Kurangnya } \\
\text { promosi di kedua } \\
\text { desa wisata ini dan } \\
\text { informasi hanya } \\
\text { dari mulut ke } \\
\text { mulut dan belum } \\
\text { efektifnya wadah } \\
\text { digital (website, } \\
\text { social media) } \\
\text { untuk mengan } \\
\text { mengarahkan } \\
\text { sebagai } \\
\text { panduan/informas } \\
\text { i } \\
\text { wisatawan yang } \\
\text { ingin mengetahui } \\
\text { potensi wisata di } \\
\text { kedua desa. }\end{array}$ & $\begin{array}{l}\text { Peningkatan } \\
\text { knowledge dan } \\
\text { soft skill } \\
\text { khususnya } \\
\text { communication } \\
\text { skill }\end{array}$ & $\begin{array}{l}\text { 1) Penyamarataan } \\
\text { pengetahuan oleh } \\
\text { masyarakat lokal Desa } \\
\text { Wisata mengenai } \\
\text { informasi potensi } \\
\text { wisata alam, wisata } \\
\text { budaya dan buatan } \\
\text { yang dapat dikunjungi } \\
\text { oleh wisatawan. } \\
\text { 2) Peningkatan } \\
\text { kemampuan untuk } \\
\text { dapat menjadi } \\
\text { Pemandu Wisata. } \\
\text { 3) Studi banding dengan } \\
\text { desa wisata yang } \\
\text { sudah rakses } \\
\text { mengelola potensi } \\
\text { wisatanya yang } \\
\text { memiliki kriteria } \\
\text { pariwisata yang } \\
\text { serupa sehingga bisa } \\
\text { belajar } \text { melalui } \\
\text { pengalaman mereka } \\
\text { dan diaplikasikan di } \\
\text { dua dua desa } \\
\text { tersebut. } \\
\text { 4) Mengikuti pelatihan, } \\
\text { seminar dan webinar } \\
\text { untuk meningkatkan } \\
\text { kemampuan } \\
\text { berkomunikasi (public } \\
\text { speaking, hospitality } \\
\text { training). } \\
\text { 5) Mengikuti pelatihan, } \\
\text { seminar dan webinar } \\
\text { mengenai digital } \\
\text { marketing untuk } \\
\text { memanfaatkan dan }\end{array}$ \\
\hline
\end{tabular}




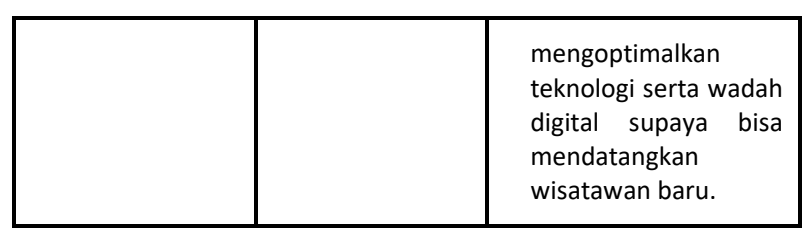

\section{KESIMPULAN}

Pelaksana kegiatan pengabdian pada masyarakat adalah tim dari Program Studi Manajemen dan Perencanaan Wilayah dan Kota (PWK) Universitas Komputer Indonesia. Pelaksanaan kegiatan dari tanggal 1 September - 30 November 2020. Kegiatan dilaksanakan dengan melaksanakan inisiasi BAPPPPEDA, identifikasi potensi desa, pengumpulan hasil survey dan dan pemaparan potensi desa dari tokoh masyarakat. Peserta kegiatan adalah Pemdes, Bumdes, Kompepar, Kelompok Wanita Tani/KWT, Karang Taruna, Pelaku Usaha UMKM, Masyarakat Sekitar/Kepala Keluarga pemilik rumah dijadikan homestay yang berkaitan dengan pengembangan desa wisata. Keberhasilan kegiatan kajian pengembanagn SDM Pariwisata diperoleh dari potensi desa dan aspirasi pemerintah dan masyarakat dalam pengembangan desa wisata di Desa Paku Alam dan Karangpakuan di kawasan jatigede Kecamatan Darmaraja Kabupaten Sumedang.

\section{UCAPAN TERIMA KASIH}

Ucapan terima kasih kepada Bupati, Setda Kabupaten dan Kepala BAPPPPEDA Sumedang, Kepala Desa serta para tokoh masyarakat, Pemdes, Bumdes, Kompepar, Kelompok Wanita Tani/KWT, Karang Taruna, Pelaku Usaha UMKM, Masyarakat Sekitar/Kepala Keluarga pemilik homestay Desa Paku Alam dan Karangpakuan yang telah memberikan kesempatan kepada tim dari Prodi Manajemen, PWK, dan Sistem Informatika untuk melaksanakan kegiatan Pengabdian pada Masyarakat.

\section{DAFTAR PUSTAKA}

[1] http://deskgram.org/p/ 1525961929456559131_1510624774.

Diakses tgl 25 Februari 2021

[2] Azwar, Saifudin, 2003, "Sikap Manusia, Teori dan Pengukurannya", Yogyakarta: Pustaka Pelajar.

[3] Dunnette, 1976, "Keterampilan Pembukuan", Jakarta: PT. Grafindo Persada.

[4] Robles, 2012, "Executive perceptions of the top 10 soft skills needed in today's workplace", Business Communication Quarterly, 75, 453-465.

[5] Depdiknas, 2004, “ Penyusunan Standar Kompetensi. Makalah Workshop, Jakarta: Departemen Kesehatan RI.

[6] IBI. 2007. 50 Tahun IBI. Ikatan Bidan Indonesia

[7] Kusumadmo. E, 2013, Manajemen Strategik-Pengetahuan, Yogyakarta, Indonesia: Cahaya Atma Pustaka.

[8] Peraturan Pemerintah Republik Indonesia Nomor 52 Tahun 2012 Tentang Sertifikasi Kompetensi Dan Sertifikasi Usaha Di Bidang Pariwisata 